\title{
Research on the Construction of Social Credit System Based on Big Data Technology
}

\author{
Mingle Zhou ${ }^{1, a}$, Yang $\mathrm{Li}^{2, b,{ }^{*}}$, Yumei $\mathrm{Li}^{3, \mathrm{c}}$, and Zhengqian Feng ${ }^{4, \mathrm{~d}}$ \\ ${ }^{1}$ Qilu University of Technology (Shandong Academy of Sciences), Shandong Computer Science \\ Center (National Supercomputer Center in Jinan), Shandong Provincial Key Laboratory of Computer \\ Networks, Jinan, China \\ 2 Shandong University, Jinan, China \\ ${ }^{3}$ Shandong institute of economic and informatization development, Jinan, China \\ ${ }^{4}$ Shandong Computer Science Center (National Supercomputer Center in Jinan), Shandong \\ Provincial Key Laboratory of Computer Networks, Jinan, China \\ aZhouml@sdas.org, b840240908@qq.com, cliym@sdas.org, dfengzhengqianf@126.com \\ ${ }^{*}$ Corresponding author: Yang Li
}

Keywords: Social credit system, Big data, Data opening, Big data platform.

\begin{abstract}
With the rapid development of China's economy and the Internet, credit data is continuously accumulating, and the trend of credit data diversification and magnanimity is obvious. Facing the diversified and massive credit data, it is necessary to analyze the credit data quickly and effectively, find the relevance of the credit data, extract the high value information from the credit data, and flexibly support the increasing demand for all kinds of credit business applications. Traditional technology cannot meet the requirements of large and complex data integration. More modern information technologies, such as big data, must be used for collection and analysis. It is of great significance to improve the effectiveness of government service and supervision, reduce costs and improve the efficiency of economic and social operation.
\end{abstract}

\section{Introduction}

Credit is the important cornerstone of the economic and social development of the city. It plays an irreplaceable role in maintaining the orderly development of the market economy and improving administrative efficiency and government credibility. The lack of credit will make the transaction cost of the whole society surge, and the efficiency of the economic operation slow down. It will also cause serious damage to the stability and development of the society ${ }^{[1]}$. The social credit system is a social mechanism based on law and morality. Through the functions of record disclosure, dissemination, and early warning of untrustworthy behaviors, the contradiction between credit and information asymmetry in economic and social life is resolved, thus punishing untrustworthy behaviors, praising honesty, and maintaining the normal order of economic activities and social life. As a result, it will promote the healthy development of economy and society. Its core function is to record the credit status of the social subject, fully mobilize the strength of the market to purify the environment, reduce the cost and risk of development, and carry forward the culture of good faith.

The construction of social credit system is divided into four aspects, namely, government credit, business integrity, social integrity and judicial public trust. Among them, government credit is the core, business integrity is the key, social integrity is the foundation, and judicial public trust is the guarantee. Administrative honesty means that the government must abide by the credit criteria for the society and the citizens, and its core is the administration in accordance with the law, trustworthiness and commitment ${ }^{[2]}$. Business integrity reflects the harmonious relationship between enterprises, enterprises and consumers. Social integrity refers to the honest and trustworthy social atmosphere formed in the whole social life. Not only personal sincerity is included, but also the widely recognized ethics and rules in social life. Judicial public belief refers to a social psychological state of trust and respect formed by the public after they have recognized and judged 
the judicial system, the judicial organs, the judicial power process and the results. China is further strengthening the construction of the social credit system. Take credit as a link, it will create a good credit environment, enhance the overall competitiveness of the country, and promote social development and civilization progress.

For example, sesame credit as a social oriented credit service system, according to the information of all aspects, using large data and cloud computing technology to objectively present personal credit status, has already provided credit services for users and businesses in nearly 100 scenes, such as consumer finance, financing lease, credit card, hotel, rental, travel, student service, public service, and so on. Since August 20, 2016, Hangzhou's citizens do not need a deposit. As long as their own sesame credits are more than 600 points, they can use umbrellas and charging treasures free of charge at 315 points, such as tourist attractions, airports, bus stations, etc., which sets a precedent in the country. All kinds of deposit are slowly disappearing, and the credit free mode is being promoted. Credit construction is far from staying at the level of individuals or institutions. It will also cover cities and even the national level. The "National City Credit Status Monitoring Platform" uses Internet information collection and data mining technology to monitor the credibility of government departments, enterprises, social organizations and judicial organs in 659 cities across the country in four aspects of government integrity, business integrity, social integrity, and judicial public trust. Through evaluation model, information mining and expert judgment, the urban comprehensive index evaluation and professional analysis report will be obtained $^{[3]}$.

\section{Factors analysis of building social credit system based on big data}

Credit evaluation depends heavily on data, and comprehensive and accurate credit data are the basic elements of a social credit system ${ }^{[4]}$. The development of the Internet makes the credit data accumulate. The main manifestations are as follows. First, it is the quantification of credit entities. Each person's behavior will become an expression of personal credit invisibly. In addition to financial credit, it also includes commercial behavior and social behavior. For example, whether driving a car obeys traffic rules, whether the library's borrowed books are returned on time, etc., can measure personal credit status from a certain point of view. Second, the credit data is dynamic. The credit evaluation results are not static, which asks us to look at personal credits and make credit decision in a dynamic way ${ }^{[5]}$. Third, credit data is unstructured. With the innovation of credit products and credit services, credit indicators are constantly adjusted and increased ${ }^{[6]}$. Meanwhile, texts, forms, pictures, audio, and video files are also stored as credit information in credit databases. In addition, third-party data obtained through web crawlers is also a major source of data in the construction of credit platforms. Therefore, as time goes on, the trend of data quantification, dynamization, and unstructured is becoming more and more obvious.

Massive credit data set higher requirements for data query, access, mining, analysis and application. Traditional technology cannot meet the requirements of large and complex data integration. It is necessary to use big data technology with high scalability and high performance for fast and effective collection, mining, analysis and processing of credit data. Meanwhile, in view of bottleneck problems of the existing credit evaluation model in big data environment, such as diversity, accuracy, and so on, a more precise and efficient collaborative filtering recommendation method will be proposed on the basis of vertical search, semantic analysis, machine learning and other technologies. Credit data analysis is carried out from more dimensions. The credit subject is evaluated comprehensively through various data. It will improve the accuracy of credit evaluation, and possible credit risk can be found in time ${ }^{[7]}$. We should strengthen credit supervision through collaborative law enforcement and joint punishment. Therefore, big data technology has wide application space in the construction of social credit system. 


\section{Design and Implementation of Social Credit System Based on Big Data}

\subsection{Promote the opening and sharing of government data}

With the continuous development of E-government in China, government work has produced a large number of data closely related to the public production and life. Government as the largest information holder, has mastered $80 \%$ of the whole social information resources. In order to serve the masses better, it is urgent for the government to open its data. At present, some provinces and cities or regions have explored the integration of big data in the region, and set up and implement the open sharing standards of data in the region. However, at the national level, there is still no shared database with extensive coverage. Therefore, it is suggested that the government should introduce government data openness and sharing rules as soon as possible, manage national data assets, and promote the opening and sharing of government data.

First of all, it will open up the data barriers between the government organizations and departments, and gradually open government data to the society. As a result, it will promote the construction of the sharing mechanism between the government data and the credit collection system, promote the comprehensive construction of the credit collection system, and actively create an administrative integrity system. Secondly, according to the degree of openness, we divide government data into different levels. All the data that involve national security, personal privacy, business secrets, etc. are used in a limited range. Other credit entity data that can promote credit construction, social governance, and economic development are opened and used according to different levels.

\subsection{Build a unified integrated credit information platform}

The development of big data technology provides technical support for integrating business data and breaking block segmentation. It can integrate credit related data on the basis of the original system, avoid duplication of construction, save cost, promote the construction progress of social credit system, and realize data sharing as soon as possible.

First, it is suggested the original system and data resources in the construction of the credit information platform of various regions and industries should be fully utilized. Big data technology will be used to integrate the credit data within and between departments. Moreover, credit data scattered in business, tax, statistics, customs and other business systems will be gathered to form provincial credit information platform. For example, Shandong public security uses big data technology to integrate the scattered data in the original business system, and builds a unified provincial police cloud data platform. It provides a good reference template for the unified credit information platform. Second, we should integrate the decentralized credit information big data platform to form a national unified credit information big data platform. In accordance with the national unified classification catalogue and data standard, on the basis of big data platform of credit information in all provinces and regions and various industries, relying on big data distribution and mass processing technology, the resources of the big data platform of each credit information are classified and collated. By means of data cleaning and data mining, credit data will be classified in a standardized way, and a national credit information big data platform will come into being. Furthermore, we will open credit data to the government, social credit agencies and individuals, according to the hierarchical authorization.

\subsection{Actively nurture big data credit industry}

Taking the construction of big data credit as the starting point to accelerate the innovation of social credit system and mechanism, the most urgent task is to cultivate the big data credit industry. We must speed up the establishment of credit standards, and ensure that credit data collection, sorting, processing, analysis and use are well founded.

First, we must establish a data acquisition mechanism combining the government and the market. At present, the state has not issued relevant policies to protect data ownership relationship, which brings various risks and obstacles for data collection of big data credit industry. We should standardize data collection through the combination of government and market. The government 
should manage the data collection of government affairs according to relevant regulations. For data of other ranges, data collection agencies and data owners negotiate the data collection. Second, we must establish the access mechanism of big data collection institutions. For some sensitive data related to national security, commercial secrets and citizen privacy, the state must establish a strict access mechanism for data acquisition institutions and allow credible institutions to take charge of data collection. Finally, the state should vigorously support the technology innovation of large data collection, increase capital investment, push forward the development of industrial chain, and accelerate the development of industrial chain including data collection, arrangement, analysis and application $^{[8]}$.

\subsection{Perfect reward and punishment system}

The mechanism of trustworthiness incentives and dishonesty punishment is the core mechanism of the operation of the social credit system, and directly affects the social subjects. With the help of big data association technology, it is necessary to speed up the construction of a cross regional and cross industry credit linkage mechanism with credit evaluation as the core, which will make believers benefit everywhere and lost believers powerless.

First of all, the reward and incentive to the trustor should be strengthened. According to the regulations, we should commend the trustworthy subjects, publicize widely and create a climate of trustworthiness and honor. In the process of market supervision and public service in finance, transportation, taxation and other departments, the application of credit information and credit products should be deepened. For the honest and trustworthy people, the "green channel", such as preferential treatment and simplified procedures, supports the incentive policy ${ }^{[9]}$. Secondly, we should strengthen the restraint and punishment of the dishonest body. In addition to existing administrative penalties, we need to establish industry blacklist system and market exit mechanism. It will promote the implementation of credit classification supervision in market supervision and public service of the people's governments at all levels. That is to say, it will combine the categories and seriousness of the dishonesty of the supervision objects, so that the dishonest persons are punished in different forms and different degrees.

\section{Summary}

The year 2017 is a crucial year for substantial progress in the development of China's social credit system, highlighting three aspects. First, the establishment of a model city for the establishment of a social credit system has played a very good leading role. At present, the construction of a national credit city is booming. Second, the signing and implementation of the joint reward and punishment memorandum has achieved remarkable results, which makes breakthroughs in the application of the construction of the social credit system. Third, credit learning is a common practice in all walks of life, laying a good foundation for the next step to better deepen the construction of the social credit system.

In general, the construction of the social credit system in China has made great progress in 2017. It can be said that it has achieved remarkable results and is getting better. In particular, it has achieved good results in the areas of joint discredit punishment, public credit information collection and sharing, electronic commerce credit risk warning monitoring, and so on ${ }^{[10]}$. The construction of China's social credit system has attracted wide attention from the international community.

In 2018, the construction of a social credit system should be more widely applied to market supervision, social governance, credit risk prevention, inclusive finance, etc., and truly serve economic development. The specific outlook is as follows. First, we must pay attention to credit management higher education and vocational education. With credit management professionals, the credit industry can go further. Second, social credit legislation must achieve breakthrough progress. By perfecting credit legislation, credit construction should gradually shift from a policy-driven model to a rule-based model. The third is to use the unified social credit code as the unique identifier of various social entities, and promote credit data collection and application of credit products. 
The next step we should continue to strengthen the construction of government integrity, business integrity, social integrity and judicial public trust, and continue to deepen the grass-roots level. And then the credit will become the business cards to which government, enterprises and individuals and other social entities will pay attention. The credit demonstration city will lead the city credit construction to a new step, promote the construction of the social credit standard system and the national social credit legislation, and improve the integrity consciousness and credit level of the whole society.

\section{Acknowledgement}

This research was financially supported by the Soft Science Research Plan of Shandong (Grant NO. 2017RZC01006).

\section{References}

[1] Song Jian, An Empirical Study on the Construction of Regional Credit Environment Index System Based on AHP and Factor Analysis, China Soft Science, vol. 6, pp.111-119, 2006.

[2] The Hunan Provincial People's Government issued a Notice on the "Hunan Provincial Social Credit System Construction Plan (2015-2020)". Official website of Hunan Provincial People's Government. 2015-06-29.

[3] Cheng Yanqiu, Credit Rating of Small Enterprises Based on Unbalanced Data, Operations Research and Management Science, vol.25, pp. 181-189, 2016.

[4] http://www.bcpcn.com/articles/403/63917.html.

[5] Jiang Hao, Big Data Required for Credit System Construction, Tsinghua Finance Review, vol.4, pp. 97-99. 2017(4).

[6] Kim, Sunghyun, Chang, Sokho, Lee, Sangwon, Consumer Trend Platform Development for Combination Analysis of Structured and Unstructured Big Data, Journal of Digital Convergence, vol.15, pp. 133-143, 2017.

[7] Yu Fengshan, Li Jin, Research on the Application of Big Data Technology in the Construction of Social Credit System, Information Technology and Informatization, vol.12, pp. 102-103,2016.

[8] Tsao,Yu-Chung, Managing default risk under trade credit: Who should implement Big-Data analytics in supply chains? Transportation Research Part E-logistics and Transportation Review, vol.106, pp. 276-293, 2017.10.

[9] Pang Sulin, Wang Shiyu, Credit computing models on farmer credit loans and its applications based on social big data information, Systems Engineering-Theory \& Practice, vol.35, pp. 837-846, 2015.

[10]Sun, Yunchuan; Li, Chunlei; Cui, Xuegang, ect., A Novel Big-data-driven Credit Reporting Framework for SMEs in China, International Conference on Identification, Information and Knowledge in the Internet of Things (IIKI), pp. 463-469, 2016. 